\title{
High-purity, isotopically enriched bulk silicon
}

\author{
J. W. Ager III, J. W. Beeman, and W. L. Hansen \\ Electronic Materials Program, Materials Sciences Division, Lawrence Berkeley National \\ Laboratory, Berkeley, CA 94720 \\ E. E. Haller ${ }^{\mathrm{a}}$, I. D. Sharp, and C. Liao \\ Electronic Materials Program, Materials Sciences Division, Lawrence Berkeley National \\ Laboratory, Berkeley, CA 94720 and \\ Materials Science and Engineering Dept., University of California at Berkeley, Berkeley, \\ CA 94720
}

\author{
A. Yang and M. L. W. Thewalt \\ Department of Physics, Simon Fraser University, Burnaby, BC, Canada
}

H. Riemann

Institut für Kristallzüchtung, Berlin, Germany

${ }^{a}$ Electronic mail: EEHaller@1bl.gov 


\section{ABSTRACT}

The synthesis and characterization of dislocation-free, undoped, single crystals of $\mathrm{Si}$ enriched in all 3 stable isotopes is reported: ${ }^{28} \mathrm{Si}(99.92 \%),{ }^{29} \mathrm{Si}(91.37 \%)$, and ${ }^{30} \mathrm{Si}$ (89.8\%). A silane-based process compatible with the relatively small amounts of isotopically enriched precursors that are practically available was used. The silane is decomposed to silicon on a graphite starter rod heated to $700-750{ }^{\circ} \mathrm{C}$ in a recirculating flow reactor. A typical run produces $35 \mathrm{gm}$ of polycrystalline $\mathrm{Si}$ at a growth rates of 5 $\mu \mathrm{m} / \mathrm{min}$ and conversion efficiency $>95 \%$. Single crystals are grown by the floating zone method and characterized by electrical and optical measurements. Concentrations of shallow dopants $(\mathrm{P}$ and $\mathrm{B})$ are as low as mid $-10^{13} \mathrm{~cm}^{-3}$. Concentrations of $\mathrm{C}$ and $\mathrm{O}$ lie below $10^{16}$ and $10^{15} \mathrm{~cm}^{-3}$, respectively.

PACS codes: 81.05.Cy, 81.10.-h, 81.10.Bk, 81.20.-n 


\section{Introduction}

There has been increasing interest in the properties of materials enriched in the stable isotopes of $\mathrm{Si}$ (natural abundance $=92.2 \%{ }^{28} \mathrm{Si}, 4.7 \%{ }^{29} \mathrm{Si}$, and $3.1 \%{ }^{30} \mathrm{Si}$ ). For example, earlier measurements of the thermal conductivity $\kappa$ of highly enriched ${ }^{28} \mathrm{Si}$ in both thin film ${ }^{12}$ and bulk ${ }^{3}$ form found increases exceeding $50 \%$ at room temperature. This is of interest to manufacturers of high-performance integrated circuits because the higher thermal conductivity of Si could be utilized to transport heat away from hot spots more effectively in a densely packed device, allowing higher operating clock rates. However, the consensus of more recent measurements is that the room temperature enhancement is actually in the range of $10-15 \% .{ }^{4}$ It has also been found that photoluminescence (PL) and impurity absorption lines in isotopically enriched ${ }^{28} \mathrm{Si}$ are extraordinarily sharp. ${ }^{678}$ Finally, a number of proposed quantum computing schemes involve the use of stable $\mathrm{Si}$ isotopes either as a spin free matrix of highly enriched ${ }^{28} \mathrm{Si}^{9}{ }^{910}$ or directly as the qubits using the ${ }^{29} \mathrm{Si}$ nuclear spin $(I=1 / 2) .{ }^{11}$ In this context, it has been reported recently that decoherence times of electrons bound to ${ }^{31} \mathrm{P}$ in enriched ${ }^{28} \mathrm{Si}$ can be greater than $10 \mathrm{~ms}$ at low temperature ${ }^{12}$ and that there is an unexpectedly long persistence of ${ }^{29} \mathrm{Si}$ spin echoes in natural $\mathrm{Si}^{13}$

Full exploration of effects of isotopic composition on a number of fundamental properties of $\mathrm{Si}$ will require material enriched in all three stable isotopes with higher chemical purity than available in the past. For example, the PL linewidths measured in refs. 6 and 8 are still 10x larger than the lifetime limit. It is also clear that practical demonstrations of Sibased quantum computing are likely to require highly enriched ${ }^{28} \mathrm{Si}$ and $/$ or ${ }^{29} \mathrm{Si}$ sources. 
We are aware of a number of previous reports on isotopically enriched ${ }^{28} \mathrm{Si}^{14}{ }^{15} 16$ and ${ }^{29} \mathrm{Si}$ and ${ }^{30} \mathrm{Si}$ crystal growth. ${ }^{17}$ While enrichments $>99 \%$ have been achieved for each isotope and some of these crystals have low concentrations of electrically active impurities (e.g. $<10^{15} \mathrm{~cm}^{-3}$ ), the combination of high chemical purity and dislocation-free crystal growth has not been achieved in every case. The relatively small quantities of enriched precursors is an important factor in this regard.

The established industrial methods for synthesizing the highest purity natural $\mathrm{Si}$ is deposition of polycrystalline $\mathrm{Si}$ (poly-Si) by the decomposition of silane ("Komatsu process") or decomposition of trichlorosilane ("Siemens process") followed by growth of single crystals by the floating zone (FZ) technique. ${ }^{18}{ }^{19}$ Crystals of up to $200 \mathrm{~mm}$ in diameter with a room temperature resistivities in excess of $30,000 \Omega$-cm are made by these processes. ${ }^{2021}$ The industrial processes are operated in a batch mode and a typical deposition run involves several hundred kilograms of poly-Si, quantities that far exceed the present supply of isotopically enriched precursors. We describe here a laboratoryscale reactor designed to convert isotopically enriched silane to poly-Si with high conversion efficiency and chemical and isotopic purity. Single crystals produced from the poly-Si by the floating zone process have excellent electronic characteristics. Such material will be valuable in performing definitive thermal conductivity measurements and in exploring a wide range of scientific and technical studies of the stable isotopes of Si. 


\section{Experimental Design}

Enriched $\mathrm{Si}$ in the form of $\mathrm{SiF}_{4}$ was obtained from the Electrochemical Plant, Zelenogorsk, Russia. The stated isotope enrichments are summarized in Table 1. All three precursor gases were contaminated by 50-100 ppm of $\mathrm{CF}_{4}, \mathrm{C}_{2} \mathrm{~F}_{6}, \mathrm{CO}_{2}, \mathrm{O}_{2}, \mathrm{HF}$, and $\mathrm{H}_{2} \mathrm{O} . \mathrm{SiF}_{4}$ was converted to $\mathrm{SiH}_{4}$ by Voltaix, Inc (North Branch, NJ). $\mathrm{CH}_{4}$ was the major measurable contaminant as measured by gas chromatography/mass spectrometry (GC/MS)and ranged from $7 \mathrm{ppm}$ in the ${ }^{28} \mathrm{SiH}_{4}$ to 70 and $100 \mathrm{ppm}$ in the ${ }^{30} \mathrm{SiH}_{4}$ and ${ }^{29} \mathrm{SiH}_{4}$, respectively. The concentrations $\mathrm{CF}_{4}, \mathrm{CO}_{2}, \mathrm{Si}_{2} \mathrm{H}_{6}$, and siloxanes were less than the 5 ppm detection limit. For production of poly-Si, the silane process $\left(\mathrm{SiH}_{4} \rightarrow \mathrm{Si}+\right.$ $2 \mathrm{H}_{2}$ ) was chosen over the trichlorosilane process based on its lower operating temperature $\left(700-900^{\circ} \mathrm{C}\right.$ vs. $\left.1100^{\circ} \mathrm{C}\right)$, higher potential conversion efficiency, and noncorrosive nature of the precursor and byproducts. ${ }^{19}$ The low corrosivity leads in general to higher purity. As discussed below, the reactor was designed with full consideration of the disadvantages of the silane process, which are primarily homogeneous nucleation and particle generation and the pyrophoric and toxic nature of silane.

An overview of the recirculating process loop is shown in Fig. 1, and a detailed drawing of the double tube reactor is shown in Fig. 2. The process gas was a dilute mixture of silane in $\mathrm{H}_{2}$ at slightly above atmospheric pressure and was recirculated with an oil-free diaphragm pump. Poly-Si growth was initiated on resistively heated $3 \mathrm{~mm}$ diameter graphite rods ( $>99.997 \%$, Goodfellow). The upper electrode contact was designed to have some axial freedom of movement to compensate for thermal expansion of the rod. A Ga-Sn eutectic solution was used to form a sliding contact with low electrical 
resistance. The rod temperature was measured before silicon deposition with an optical pyrometer. During the deposition process, the temperature was measured by imaging light from the poly-Si rod through a $880 \mathrm{~nm}$ bandpass filter onto a Si photodiode. It was necessary to continuously increase the power to the rod as its diameter increased due to increased rates of radiative and convective cooling; typical power settings were $440 \mathrm{~W}$ at the beginning of a run and $1.4 \mathrm{~kW}$ at the end of a run when the rod had grown to a diameter of $12 \mathrm{~mm}$.

In order to maintain a constant process loop pressure, the loop had to be exhausted at rate approximately equal to twice the silane feed. Based on reported data from industrial users of the Komatsu process, particle generation on the order of $1 \mathrm{wt} . \%$ of the deposited poly-Si might be expected. A suitable filter was fabricated from a porous 316 stainless steel. The filter contributed a less than 10 torr pressure drop to the process loop. No evidence of particles downstream of the filter was observed. The silane concentration in the process loop was monitored by sampling the process gas at 6 minute intervals by a gas chromatograph $\left(1 / 8^{\prime \prime} \times 6^{\prime}\right.$ Porapak $\mathrm{N}$ column at $\left.30^{\circ} \mathrm{C}\right)$ equipped with a thermal conductivity detector. Calibration runs were performed frequently with a $1 \%$ silane in hydrogen standard. The estimated minimum detectable silane concentration was $0.02 \%$.

Care was taken to operate the reactor to achieve uniform deposition along the rod and minimum particle generation. In a flow tube reactor, if the effective deposition rate is too high, the silane concentration will decrease as the process gas transits the reactor and the resultant poly-Si rod will not be uniform in thickness. The effective deposition rate can 
be reduced by reducing the rod temperature and/or increasing flow rate. In a one-pass reactor, this would decrease the overall conversion efficiency. However, gas recirculation allows the gas velocity to be increased while maintaining high conversion efficiency. An increased gas velocity also can be used to reduce the volume of the reactor that is above $400^{\circ} \mathrm{C}$, which is the threshold particle generation by the homogeneous nucleation of silane.

Hydrodynamic modeling was used to select the process conditions using methods developed by Hashimoto et al..$^{22}$ The industrial silane process operates at ca. $800^{\circ} \mathrm{C}$ with silane concentrations in $\mathrm{H}_{2}$ in the range of $1.5-5 \%{ }^{23}{ }^{24}$ Here it was found to be advantageous to operate at flow of $15 \mathrm{slpm}$ at a somewhat lower temperature $\left(730^{\circ} \mathrm{C}\right)$ and in a silane concentration range $(0.3-0.5 \%)$ to decrease particulate formation. Particulate formation was observed on the walls of the reactor near the outlet after a few hours of operation but did not seem to affect the quality of the poly-Si or the observed yield ( $>95 \%$ ). The typical deposition time was 16 hours to grow a rod with a diameter of $12 \mathrm{~mm}$ and a mass of $33-36 \mathrm{gm}$. The average deposition rate was $5 \mu \mathrm{m} / \mathrm{min}$ which is comparable to that of industrial reactors. The graphite starter rod was removed from the poly-Si by a combination of drilling and lapping. Thorough etching with a 1:10 mixture of $\mathrm{HF}$ and $\mathrm{HNO}_{3}$ was used to remove mechanical damage and residual graphite or $\mathrm{SiC}$ grains. Sections of the poly rods were converted to dislocation-free single crystal Si in a floating zone (FZ) crystal puller. In the case of ${ }^{28} \mathrm{Si}$ and ${ }^{29} \mathrm{Si}$ isotopically enriched seeds were used. A natural seed was used for ${ }^{30} \mathrm{Si}$. 


\section{Results and Discussion}

Initial tests of the full synthesis process were performed with natural silane with a stated purity of $99.999 \%$. Typical room temperature resistivities of the natural FZ crystals were in the 3-10 $\mathrm{k} \Omega$ range (p-type), corresponding to a room temperature carrier concentration of less than $10^{13} \mathrm{~cm}^{-3}$. This demonstrates that our process is capable of making Si whose purity is only limited by that of the precursor silane.

Enriched single crystals are shown in Fig. 3. SIMS measurements of the isotopic composition are summarized in Table 1. With the exception of the ${ }^{30} \mathrm{Si}$ crystal, which has an enrichment gradient from the seed to the tail due to partial melting of the natural seed isotopic enrichments of the crystals are the same as those of the precursor gas. Temperature dependent Hall effect data are shown in Fig. 4. All crystals were n-type. In the ${ }^{28} \mathrm{Si}$ crystal, the net-carrier concentration was $3 \times 10^{14} \mathrm{~cm}^{-3}$ at the seed end and $5 \times 10^{15}$ $\mathrm{cm}^{-3}$ at the tail; this distribution is attributed to the expected segregation of the $\mathrm{P}$ to the tail region during FZ growth. For the ${ }^{29} \mathrm{Si}$ and ${ }^{30} \mathrm{Si}$ enriched crystals, the net carrier concentration was in the mid $10^{13} \mathrm{~cm}^{-3}$ range. Room temperature mobilities for $\mathrm{n}$-type material were between 1220 and $1360 \mathrm{~cm}^{2} \mathrm{~V}^{-1} \mathrm{~s}^{-1}$ and increased monotonically down with $\mathrm{T}^{-3 / 2}$ to $20 \mathrm{~K}$. This shows that the crystals have a very low acceptor compensation resulting in very low ionized impurity scattering at low temperatures.

Low temperature PL was performed using techniques described in detail elsewhere. ${ }^{25}$ Analysis of the TO-assisted transitions showed that $\mathrm{P}$ was the majority donor in all cases and that the concentration of B was typically 10x lower, consistent with the Hall data. 
Spectra showing the no-phonon phosphorus-bound exciton $\left(\mathrm{P}_{\mathrm{NP}}\right)$ transition are presented in Fig. 4. The effect of the isotopic composition in renormalizing the bandgap is seen clearly. It is interesting to compare the spectra to prior measurements of enriched $\mathrm{Si}$ crystals. For the ${ }^{28} \mathrm{Si}$ crystals, the observed FWHM is near-instrument-limited at 0.022 $\mathrm{cm}^{-1}$. More detailed analysis by $\mathrm{PLE}^{26}$ showed that the linewidth is just slightly wider than the narrowest reported in ${ }^{28} \mathrm{Si}$ to date. 6 For ${ }^{29} \mathrm{Si}$, the line was slightly split (inset of Fig. 5). Assigning the splitting to strains caused by the presence of substitutional carbon, a carbon concentration of $2 \times 10^{17} \mathrm{~cm}^{-3}$ was estimated. ${ }^{27}$ This is in reasonable agreement with a subsequent SIMS measurement which found a carbon concentration of $6 \times 10^{16}$ $\mathrm{cm}^{-3}$. It should be noted that this crystal was grown from silane that had the highest level of methane contamination. Based on the absence of splitting of the $\mathrm{P}_{\mathrm{NP}}$ PL line carbon concentrations were below $10^{16} \mathrm{~cm}^{-3}(200 \mathrm{ppb})$ in both the ${ }^{28} \mathrm{Si}$ and ${ }^{30} \mathrm{Si}$ enriched crystals. This is notable given the ppm levels of $\mathrm{CH}_{4}$ in the silane used for their growth. In the case of ${ }^{29} \mathrm{Si}$ and ${ }^{30} \mathrm{Si}$, the PL linewidths were much narrower than previously reported for crystals enriched in these two isotopes. 25

\section{Conclusions}

A process consisting of high-yield production of isotopically enriched bulk polycrystalline Si in a laboratory scale reactor followed by float zone crystallization has been demonstrated to produce dislocation-free single crystals enriched in all three stable isotopes of $\mathrm{Si}\left({ }^{28} \mathrm{Si},{ }^{29} \mathrm{Si}\right.$, and $\left.{ }^{30} \mathrm{Si}\right)$. The $99.9+\%{ }^{28} \mathrm{Si}, 91 \%{ }^{29} \mathrm{Si}$, and $90 \%{ }^{30} \mathrm{Si}$ crystals made in this study are among the highest quality isotopically enriched Si made to date with electrically active impurities at $10^{15} \mathrm{~cm}^{-3}$ and below, low carbon concentrations, and 
minimal amounts of inhomogeneous lattice strain. Isotopically enriched crystals of still higher purity and enrichment can be grown when high purity, more highly enriched, precursor gases become available.

\section{Acknowledgments}

This work was supported by the Initiatives for Proliferation Prevention Program of the Office of Nonproliferation Research and Engineering (NN-20) of the U. S. Department of Energy under contract DE-AC03-76SF00098. We acknowledge technical assistance with reactor operation from Andreana and useful discussions with S. Burden, H. Dawson, R.

Reis, J. Maurits, T. Cizsek, M. Chandra, P. Hannah, A. Arvidson, J. Reimer, and S. M. Lord. We especially thank M. Kowase for providing detailed schematics of the Kyoto University poly-Si reactor. 
Table 1. Summary of isotopic composition measurement in the precursor gas and in the enriched single crystals. The gas measurements were performed by GC-MS and the crystal measurements were performed with SIMS. Due to the use of an natural Si seed during float zone growth, the ${ }^{30} \mathrm{Si}$ enriched crystal has an isotopic gradient. Data for the tail of the crystal, where the enrichment is highest, are presented.

\begin{tabular}{lrrrrrrr}
\hline \hline isotope & nat. & \multicolumn{2}{c}{${ }^{28} \mathrm{Si}$ enriched } & \multicolumn{2}{c}{${ }^{29} \mathrm{Si}$ enriched } & \multicolumn{2}{c}{${ }^{30} \mathrm{Si}$ enriched } \\
at. $\%$ & $\mathrm{Si}$ & $\mathrm{SiF}_{4}$ & crystal & $\mathrm{SiF}_{4}$ & crystal & $\mathrm{SiF}_{4}$ & crystal \\
${ }^{28} \mathrm{Si}$ & 92.23 & 99.93 & 99.92 & 4.26 & 4.32 & 2.00 & 2.50 \\
${ }^{29} \mathrm{Si}$ & 4.67 & 0.065 & 0.075 & 91.37 & 91.37 & 7.35 & 7.70 \\
${ }^{30} \mathrm{Si}$ & 3.10 & 0.005 & .005 & 4.37 & 4.30 & 90.65 & 89.80
\end{tabular}




\section{Figure captions}

Fig. 1. Polysilicon reactor: overview of process loop.

Fig. 2. Polysilicon reactor: reaction zone detail.

Fig. 3. Dislocation-free single crystals of isotopically enriched Si.

Fig. 4. Variable temperature Hall effect data for isotopically enriched Si crystals: $99.92 \%$ ${ }^{28} \mathrm{Si}, 91.37 \%{ }^{29} \mathrm{Si}$ (seed end), and $86.7 \%{ }^{30} \mathrm{Si}$ (seed end). All crystals are n-type. The net carrier concentration is higher in the tail end of the ${ }^{28} \mathrm{Si}$ crystal compared to the seed end due to $\mathrm{P}$ segregation during the float zone growth. A dashed line indicates the $\mathrm{T}^{-3 / 2}$ dependence for the mobility data.

Fig. 5. Photoluminescence spectra obtained at $4 \mathrm{~K}$ of the $\mathrm{P}_{\mathrm{NP}}$ transition in enriched $\mathrm{Si}$ single crystals. Positions and linewidths are: ${ }^{28} \mathrm{Si}: 9274.18 \mathrm{~cm}^{-1}, 0.022 \mathrm{~cm}^{-1} ;{ }^{29} \mathrm{Si}$ : $9282.9,0.013 \mathrm{~cm}-1$ (line is split due to substitutional carbon incorporation, see inset and text); ${ }^{30} \mathrm{Si}$ with two different enrichments due to natural Si incorporation during FZ growth: 9289.15 and $9290.18 \mathrm{~cm}^{-1}, 0.064 \mathrm{~cm}^{-1}$, respectively. The location of the transition in natural $\mathrm{Si}$ is indicated with an arrow. 


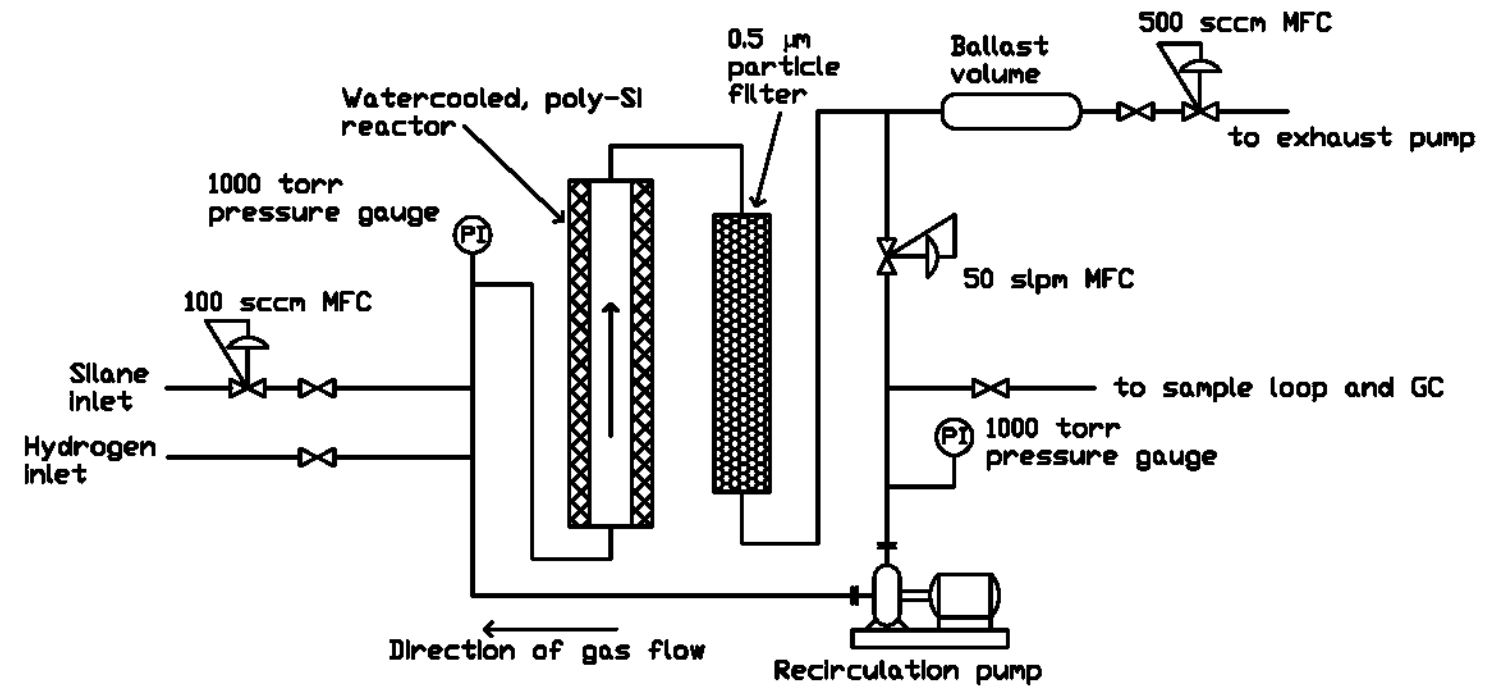

Fig. 1. Polysilicon reactor: overview of process loop. 


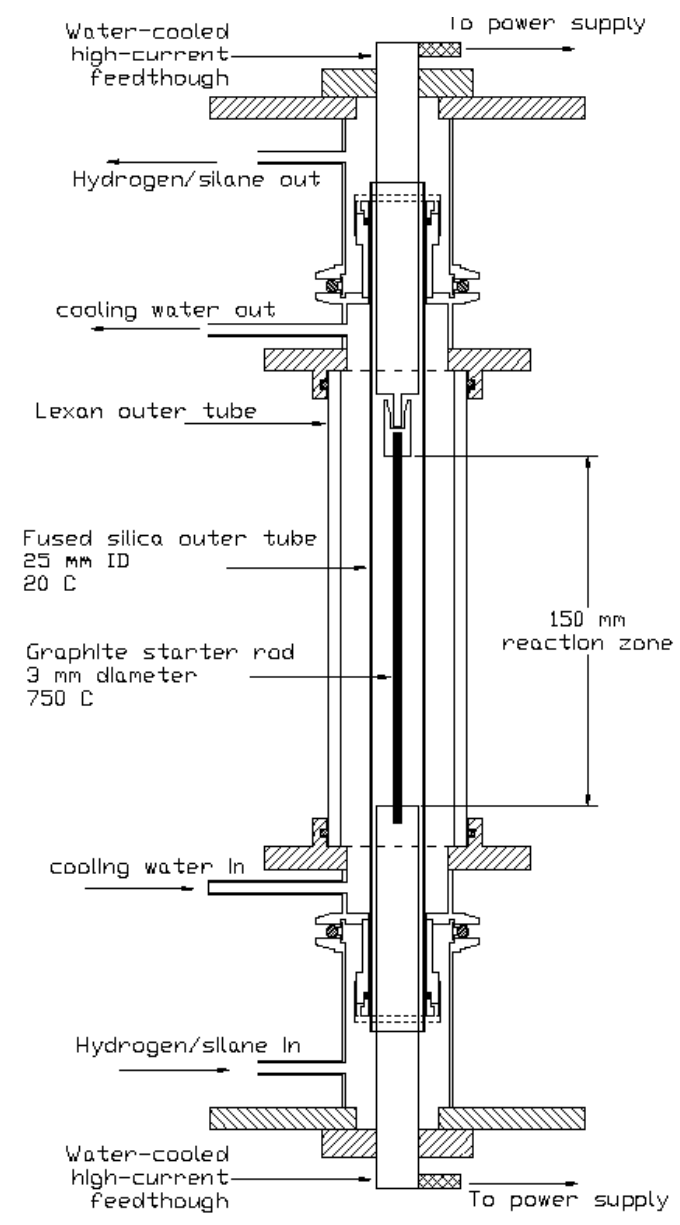

Fig. 2. Polysilicon reactor: reaction zone detail. 


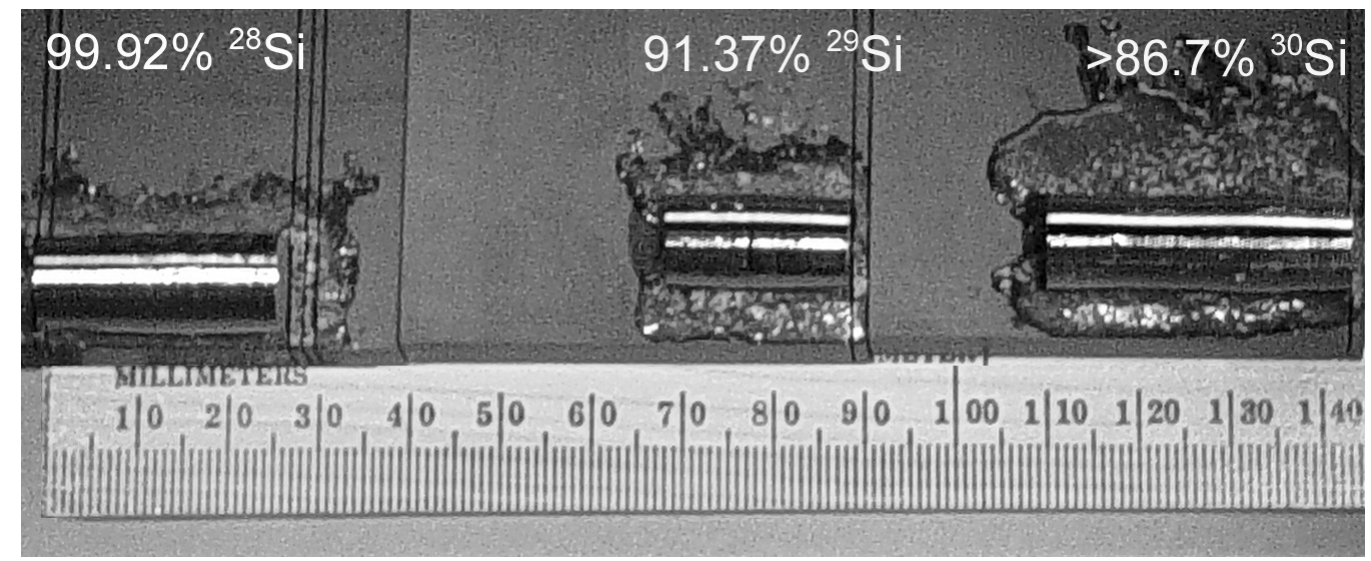

Fig. 3. Dislocation-free single crystals of isotopically enriched Si. 

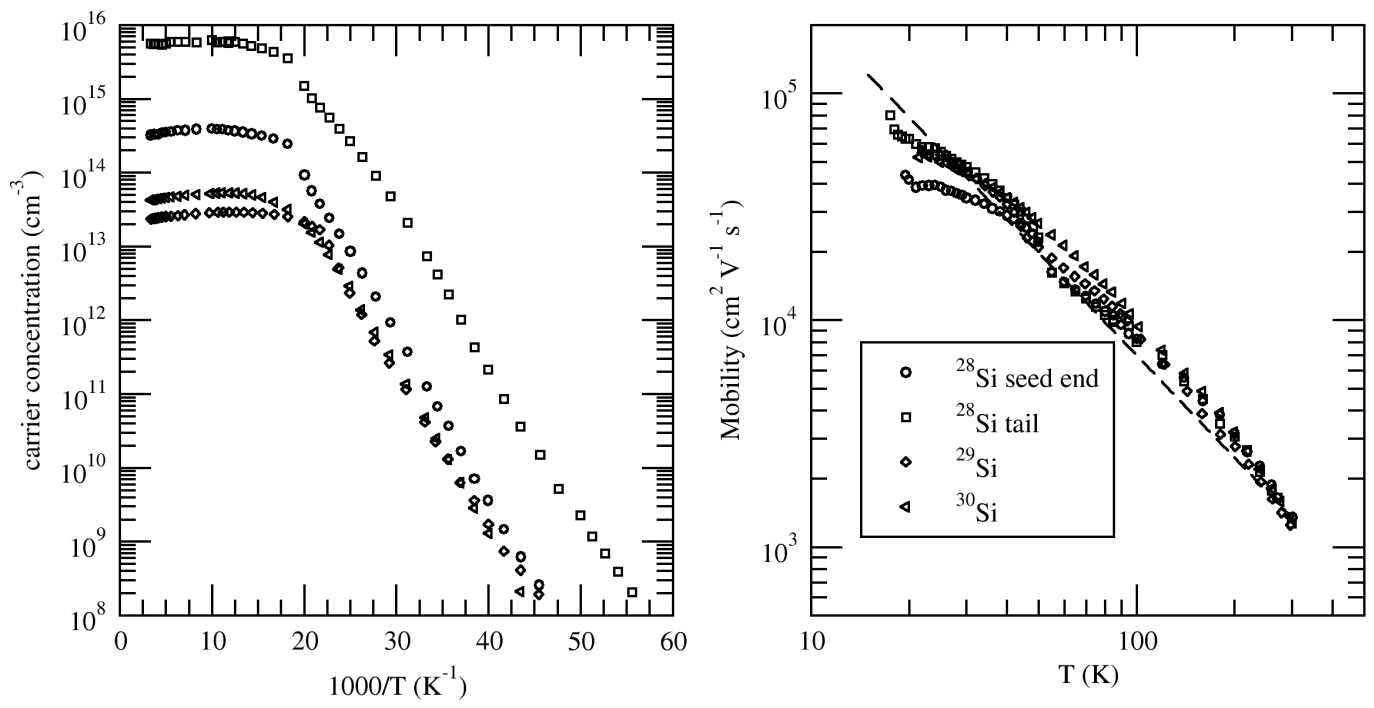

Fig. 4. Variable temperature Hall effect data for isotopically enriched Si crystals: $99.92 \%{ }^{28} \mathrm{Si}, 91.37 \%{ }^{29} \mathrm{Si}$ (seed end), and $86.7 \%{ }^{30} \mathrm{Si}$ (seed end). All crystals are ntype. The net carrier concentration is higher in the tail end of the ${ }^{28} \mathrm{Si}$ crystal compared to the seed end due to $P$ segregation during the float zone growth. A dashed line indicates the $T^{-3 / 2}$ dependence for the mobility data. 


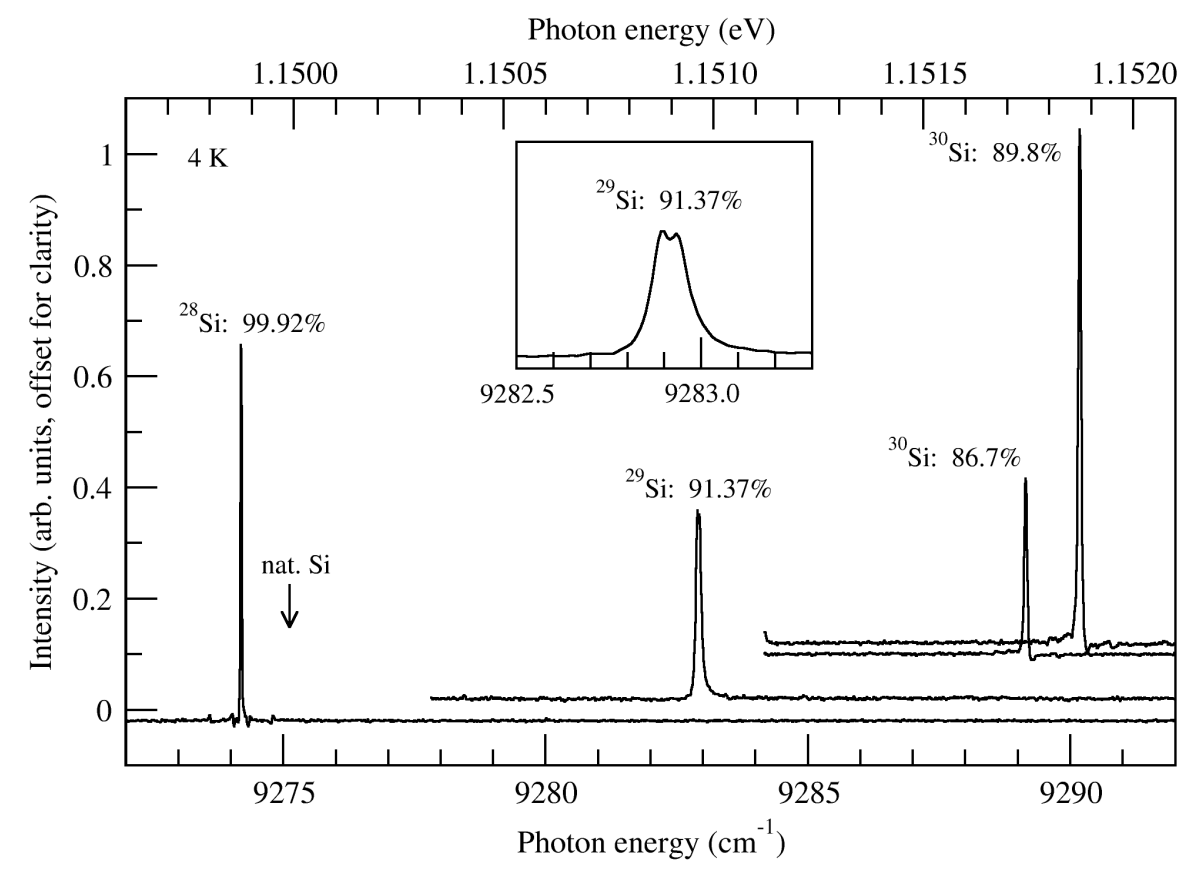

Fig. 5. Photoluminescence spectra obtained at $4 \mathrm{~K}$ of the $\mathbf{P}_{\mathrm{NP}}$ transition in enriched Si single crystals. Positions and linewidths are: ${ }^{28}$ Si: $9274.18 \mathrm{~cm}^{-1}, 0.022 \mathrm{~cm}^{-1} ;{ }^{29} \mathrm{Si}$ : 9282.9, $0.013 \mathrm{~cm}-1$ (line is split due to substitutional carbon incorporation, see inset and text); ${ }^{30}$ Si with two different enrichments due to natural Si incorporation during FZ growth: 9289.15 and $9290.18 \mathrm{~cm}^{-1}, 0.064 \mathrm{~cm}^{-1}$, respectively. The location of the transition in natural Si is indicated with an arrow. 
1 W. S. Capinski, H. J. Maris, E. Bauser, I. Sillier, M. Asen-Palmer, T. Ruf, M. Cardona, and E. Gmelin, Appl. Phys. Lett. 71, 2109 (1997).

${ }^{2}$ P. L. Komarov, M. G. Burzo, G. Kaytaz, and P. E. Raad, Microelectronics Journal 34 $1115(2003)$.

3 T. Ruf, R. W. Henn, M. Asen-Palmer, E. Gmelin, M. Cardona, H.-J. Pohl, G. G.

Devyatych, P. G. Sennikov, Solid State Commun. 115, 243 (2000).

4 A. V. Inyushkin, Inorganic Materials 38, 427 (2002).

5 T. Ruf, R. W. Henn, M. Asen-Palmer, E. Gmelin, M. Cardona, H.-J. Pohl, G. G.

Devyatych, and P. G. Sennikov, Solid State Commun. 127, 257 (2003).

${ }^{6}$ D. Karaiskaj, M. L. W. Thewalt, T. Ruf, M. Cardona, H.-J. Pohl, G. G. Deviatych, P.

G. Sennikov, and H. Riemann, Phys. Rev. Lett. 86, 6010 (2001).

${ }^{7}$ D. Karaiskaj, M. L. W. Thewalt, T. Ruf, M. Cardona, and M. Konuma, Phys. Rev. Lett. 89, 016401 (2002).

${ }^{8}$ D. Karaiskaj, J. A. H. Stotz, T. Meyer, M. L. W. Thewalt, and M. Cardona, Phys. Rev. Lett. 90, 186402 (2003).

9 B E. Kane, Nature 393, 133 (1998).

${ }^{10}$ R. Vrijen, E. Yablonovitch, H. W. Jiang, A. Balandin, V. Roywhowdhury, T. Mor, and D. DiVincenzo, Phys. Rev. A 62, 0123306 (2000).

11 T. D. Ladd, J. R. Goodman, F. Yamaguchi, Y. Yamamoto, E. Abe, and K. M. Itoh, Phys. Rev. Lett. 89, 017901 (2002). 
${ }^{12}$ A. M. Tyryshkin, S. A. Lyon, A. V. Astashkin, and A. M. Raitsimring, Phys. Rev. B 68, 193207 (2003).

13 A. E. Dementyev, D. Li, K. MacLean, and S. E. Barrett, Phys. Lett. B 68, 153302 (2003).

14 P. Becker, H. Bettin, P. De Bièvre, C. Holm, U. Kütgens, F. Spieweck, J. Stümpel, S. Valkiers, and W. Zulehner, IEEE Trans. Instr. Meas. 44, 522 (1995).

15 K. Takyu, K. M. Itoh, K. Oka, N. Saito, and V. I. Ozhogin, Jpn. J. Appl. Phys., Part 2 38, L1493 (1999).

16 A. D. Bulanov, G. G. Devyatych, A. V. Gusev, P. G. Sennikov, H.-J. Pohl, H. Riemann, H. Schilling, and P. Becker, Cryst. Res. Technol. 35, 1023 (2000).

${ }^{17}$ K. M. Itoh, J. Kato, M. Uemura, A. K. Kaliteyevskii, O. N. Godisov, G. G. Devyatych, A. D. Bulanov, A. V. Gusev, I. D. Kovalev, P. G. Sennikov, H.-J. Pohl, N. V. Abrosimov, and H. Riemann, Jpn. J. Appl. Phys. 42, 6248 (2003).

18 S. Wolf and R. N. Tauber, Silicon Processing for the VSLI Era (Lattice Press, Sunset Beach, CA, 1999), Vol. 1, pp.6-35.

19 T. D. Kamins, in Handbook of Semiconductor Silicon Technology, edited by W. C. O’Mara, R. B. Herring, and Lee P. Hunt (Williams-Andrew, Norwich, NY, 1990), pp. 640-719.

20 R. N. Flagella, and H. J. Dawson, U.S. Patent No. 4,921,026 (May 1, 1990).

21 W. Hensel, in Electrochemical Society Proceedings, Vol. 96-13, edited by C. L.

Claeys, P. Stallhofer, P. Rai-Choudhury, and J. E. Maurtis JE. (Electrochemical Society, Pennington, NJ, 1996), pp. 3-14. 
${ }^{22}$ K. Hashimoto, K. Miura, T. Masuda, M. Toma, H. Sawai, and J. Kawase, J. Electrochem. Soc. 137, 1000 (1990).

${ }^{23}$ Y. Yatsurugi, A. Yusa, and N. Takahashi, U.S. Patent No. 4,150,168 (Apr. 17, 1979).

${ }^{24}$ W. C. Breneman, R. N. Flagella, J. M. Gaston, and D. W. Hagan, U.S. Patent No. 4,826,668 (May 2, 1989).

${ }^{25}$ D. Karaiskaj, M. L. W. Thewalt, T. Ruf, and M. Cardona, phys. stat. sol. (b) 235, 63 (2003).

${ }^{26}$ M. L. W. Thewalt, private communication.

27 A. N. Safonov, G. Davies, and E C. Lightfowlers, Phys. Rev. B 54, 4409 (1996). 